\title{
Home-Based HIV Counseling and Testing as a Gateway to Earlier Initiation of Antiretroviral Therapy
}

\author{
Edward J. Mills ${ }^{\mathbf{1}}$ and Nathan Ford ${ }^{2,3}$ \\ ${ }^{1}$ Faculty of Health Sciences, University of Ottawa, Canada; ${ }^{2}$ Médecins Sans Frontières, Geneva, Switzerland; and ${ }^{3}$ Centre for Infectious Disease Epidemiology and \\ Research, University of Cape Town, South Africa
}

(See the article by Wachira et al, on pages 275-81.)

Timely access to combination antiretroviral therapy (ART) represents the single most effective intervention in reducing mortality and morbidity among patients with human immunodeficiency virus (HIV) infection or AIDS. Until recently, the threshold for initiating ART in resource-limited settings was set at a CD4 T-cell count $\leq 200$ cells $/ \mathrm{mm}^{3}$, a conservative threshold that had been abandoned in wealthier settings several years earlier [1].

Randomized trial data [2] and cohort evaluations [3] that demonstrate improved survival when ART is initiated earlier provided convincing evidence for the World Health Organization to revise guidance for resource-limited settings to initiate ART at a CD4 T-cell count $\leq 350$ cells $/ \mathrm{mm}^{3}$. Most developing countries have now adopted or strive for this target threshold. More recent studies have validated this shift by demonstrating the broader benefits of earlier initiation of ART, including reduced incidence of

Received 21 September 2011; accepted 26 September 2011

Correspondence: Edward J. Mills, PhD, University of Ottawa, 43 Templeton, Ottawa, Ontario, K1N 6X1, Canada 7783178530 (edward.mills@uottawa.ca).

Clinical Infectious Diseases 2012;54(2):282-4 (C) The Author 2011. Published by Oxford University Press on behalf of the Infectious Diseases Society of America. All rights reserved. For Permissions, please e-mail: journals.permissions@ oup.com.

DOI: 10.1093/cid/cir812 tuberculosis [4], reduced rates of hospitalization [5], reduced likelihood of HIV transmission [6], and increased life expectancy [7].

Changing the threshold for initiation was seen as a daunting task, and a common refrain in discussions about early ART initiation in resource-limited settings was that raising the threshold would overwhelm healthcare systems by increasing the number of new patients requiring a clinician's time [8]. It has often been pointed out that most patients in sub-Saharan Africa present too late as it is, with an average CD4 $\mathrm{T}$ cell count of only $111 \mathrm{cells} / \mathrm{mm}^{3}$ [9]. For the most part, however, the reasons that patients present late to care have nothing to do with initiation thresholds at the clinic. Rather, they are related to a lack of awareness of their HIV status [10] or disincentives to accessing care, such as high costs [11] or distances from clinics [12]. There is no convincing evidence that individuals arrive late to care because they have been "crowded out" by patients who are not as sick. Earlier treatment means that patients do not become as sick and thus need less-complex care. Evidence from programs to date suggests that earlier initiation supports access to care by promoting delivery of ART by nurse-led primary care clinics and reducing demands for more-specialized and inpatient clinical care [5].
Although considerable research attention has been paid to demonstrating the relative merits of earlier ART initiation, the question of how to encourage persons to seek treatment earlier has to date been almost entirely neglected. Recently, the need for better retention in care between testing and initiation of treatment for eligible patients has been recognized [13]. An important prior concern is to identify patients as early as possible, both to decrease the likelihood of transmission between partners and to provide an early opportunity to engage patients into care.

Home-based counseling and testing (HBCT) represent an important strategy for identifying patients before their CD4 $\mathrm{T}$ cells are severely depleted. It is also a strategy to engage underrepresented populations in HIV/AIDS testing. Populations such as men, the elderly, and adolescents [14, 15] are regularly excluded from testing campaigns and are thus underrepresented in ART treatment programs, leading to worse overall mortality for these groups [16]. Designers of targeted HBCT that aim to broadly involve either the entire population in a setting or an accurate sample of it need to consider whether these groups are likely to be identified through HBCT or more likely to be located outside the home [17].

The study by Wachira and colleagues provides compelling evidence that widespread HIV counseling HBCT helps identify 
infected individuals earlier in their disease progression [18]. HBCT also identified more discordant couples compared with more common, clinic-based entry points to HIV testing, indicating the potential for HBCT to contribute to a reduction in HIV transmission. In this regard, HBCT should become an important strategy for implementing long-standing recommendations to test household members of HIVinfected persons [19] and will lend support to the forthcoming World Health Organization recommendations for earlier ART initiation in discordant couples.

The results of this study should provide an urgently needed impetus for ART providers to look beyond the clinic and explore how best to provide expanded access to testing. Home- and communitybased approaches can help increase access to testing and care, identify discordant couples, and ensure that testing can be linked with knowledge of HIV infection, general health, and possibly unrelated health issues that are of importance to families. HBCT represents an important opportunity to accurately document the prevalence (and incidence when repeated) of HIV infection and other diseases in a community.

Past criticisms of AIDS exceptionalism have been tempered by effective transitioning of HIV programs from vertical to a more integrated programs, with HIV care delivered as one component of primary care. Such positive synergies could also be extended to HBCT. Home visits by broadly trained health workers could provide a gateway for advice and education regarding other important conditions, such as active case finding for tuberculosis [20] and screening for risk factors for diabetes and cardiovascular diseases [21].

It is possible that interventions such as HBCT will create a leapfrogging effect for health systems in sub-Saharan Africa. Although home-based care is uncommon in wealthier settings, it is an important entry point for care in resource-limited areas, particularly in rural settings. Evidence from Médecins Sans Frontières programs in Mozambique already display very positive outcomes from village and homebased HIV treatment, led by village member volunteers, with very low rates of mortality $(2 \%)$ and attrition from ART $(0.2 \%)$ [22]. It seems likely that such initiatives will become more common as the evidence for community- and home-based care becomes more convincing and as physician shortages mandate the shifting of tasks from skilled to less-skilled individuals.

The broader implementation of HBCT should be accompanied by operational research to fine-tune implementation approaches for different contexts. Wachira and colleagues rightly note that the costeffectiveness of HBCT needs to be documented. Given that earlier initiation of ART reduces morbidity and mortality and has been demonstrated to be cost-effective [23], costing studies should take into account the costs associated with lower rates of survival and subsequent life expectancy for patients accessing ART with low CD4 $\mathrm{T}$ cell counts. Ethical concerns will also doubtless be raised, particularly for settings where stigma concerning HIV/AIDS continues to be a major concern. Previous efforts to expand HIV testing through household and community programs have been criticized as violating human rights [24]. Reassuringly, in this study, HBCT had a high rate of acceptance, a finding consistent with those of other studies [25]; many criticisms raised about past campaigns could be avoided through adequate planning and training. Operational research will be important in determining how to ensure broad acceptance of HBCT. Finally, recent research has shown that the provision of a patient's CD4 T cell count at the time of testing increases ART initiation rates [26]. This raises the potential for innovative approaches that would integrate point-of-care CD4 $\mathrm{T}$ cell counts into HBCT programs [27].

Ten years ago it was suggested that "[ $t$ ] he quest for secrecy promotes rather than breaks the destructive silence around
HIV/AIDS, and divides the known infected from the undiagnosed and uninfected" [28]. We now also know that limiting access to testing also limits timely access to care, to the harm of both HIVpositive and HIV-negative individuals. Program implementers are compelled by the latest evidence and guidelines to enroll persons into care earlier but have been given few guidelines as to how to go about it. HBCT appears to be a feasible and acceptable approach that can further both HIV treatment and prevention objectives and potentially support broader health objectives.

\section{Note}

Potential conflicts of interest. All authors: No reported conflicts.

All authors have submitted the ICMJE Form for Disclosure of Potential Conflicts of Interest. Conflicts that the editors consider relevant to the content of the manuscript have been disclosed.

\section{References}

1. Phillips AN, Gazzard BG, Clumeck N, Losso MH, Lundgren JD. When should antiretroviral therapy for HIV be started? BMJ 2007; 334:76-8.

2. Severe P, Juste MA, Ambroise A, et al. Early versus standard antiretroviral therapy for HIV-infected adults in Haiti. N Engl J Med 2010; 363:257-65.

3. Sterne JA, May M, Costagliola D, et al. Timing of initiation of antiretroviral therapy in AIDS-free HIV-1-infected patients: a collaborative analysis of 18 HIV cohort studies. Lancet 2009; 373:1352-63.

4. Grinsztejn B RH, Cohen MS, et al. Effects of early versus delayed initiation of antiretroviral therapy (ART) on HIV clinical outcomes: results from the HPTN 052 randomized clinical trial [abstract MOAX0105]. Sixth International AIDS Society Conference on HIV Pathogenesis, Treatment and Prevention. 17-20 July 2011. Rome Geneva, Switzerland: IAS.

5. Ford N, Kranzer K, Hilderbrand $\mathrm{K}$, et al. Early initiation of antiretroviral therapy and associated reduction in mortality, morbidity and defaulting in a nurse-managed, community cohort in Lesotho. AIDS 2010; 24: 2645-50.

6. Cohen MS, Chen YQ, McCauley M, et al. Prevention of HIV-1 infection with early antiretroviral therapy. N Engl J Med 2011; 365:493-505.

7. Mills EJ, Bakanda C, Birungi J, et al. Life expectancy of persons receiving combination antiretroviral therapy in low-income 
countries: a cohort analysis from Uganda. Ann Intern Med 2011; 155:209-16.

8. Cullinan $\mathrm{K}$. What's good for the individual might crash the system. Health-E News. 2008. http://www.health-e.org.za/news/article.php? uid $=20032045$. Accessed 1 September 2011.

9. May M, Boulle A, Phiri S, et al. Prognosis of patients with HIV-1 infection starting antiretroviral therapy in sub-Saharan Africa: a collaborative analysis of scale-up programmes. Lancet 2010; 376:449-57.

10. Kranzer K, van Schaik N, Karmue U, Middelkoop $\mathrm{K}$, et al. High prevalence of self-reported undiagnosed HIV despite high coverage of HIV testing: a cross-sectional population based sero-survey in South Africa. PLos One 2011; 6:e25244.

11. Zachariah R, Harries AD, Manzi M, et al. Acceptance of anti-retroviral therapy among patients infected with HIV and tuberculosis in rural Malawi is low and associated with cost of transport. PLoS One 2006; 1:e121.

12. Miller CM, Ketlhapile M, Rybasack-Smith $\mathrm{H}$, Rosen S. Why are antiretroviral treatment patients lost to follow-up? A qualitative study from South Africa. Trop Med Int Health 2010; 15:48-54.

13. Rosen S, Fox MP. Retention in HIV care between testing and treatment in sub-Saharan Africa: a systematic review. PLoS Med 2011; 8:e1001056.

14. Bakanda C, Birungi J, Mwesigwa R, et al. Survival of HIV-infected adolescents on antiretroviral therapy in Uganda: findings from a nationally representative cohort in Uganda. PLoS One 2011; 6:e19261.
15. Bakanda C, Birungi J, Mwesigwa R, et al. Association of aging and survival in a large HIV-infected cohort on antiretroviral therapy. AIDS 2011; 25:701-5.

16. Muula AS, Ngulube TJ, Siziya S, et al. Gender distribution of adult patients on highly active antiretroviral therapy (HAART) in Southern Africa: a systematic review. BMC Public Health 2007; 7:63.

17. Kuwane B, Appiah K, Felix M, Grant A, Churchyard G. Expanding HIV care in Africa: making men matter in Johannesburg. Lancet 2009; 374:1329.

18. Wachira J, Kimaiyo S, Ndege S, Mamlin J, Braitstein P. What is the impact of homebased HIV counseling and testing (HBCT) on the clinical status of newly enrolled adults in a large HIV care program in western Kenya? Clin Infect Dis 2012; 54:275-81.

19. Were WA, Mermin JH, Wamai N, et al. Undiagnosed HIV infection and couple HIV discordance among household members of HIV-infected people receiving antiretroviral therapy in Uganda. J Acquir Immune Defic Syndr 2006; 43:91-5.

20. Corbett EL, Bandason T, Duong T, et al. Comparison of two active case-finding strategies for community-based diagnosis of symptomatic smear-positive tuberculosis and control of infectious tuberculosis in Harare, Zimbabwe (DETECTB): a clusterrandomised trial. Lancet 2010; 376:1244-53.

21. Maher D, Waswa L, Baisley K, Karabarinde A, Unwin N, Grosskurth H. Distribution of hyperglycaemia and related cardiovascular disease risk factors in low-income countries: a cross-sectional population-based survey in rural Uganda. Int J Epidemiol 2011; 40: 160-71.

22. Decroo T, Telfer B, Biot M, et al. Distribution of antiretroviral treatment through selfforming groups of patients in Tete province, Mozambique. J Acquir Immune Defic Syndr 2011; 56:e39-e44.

23. Koenig SP, Bang H, Severe P, et al. Costeffectiveness of early versus standard antiretroviral therapy in HIV-infected adults in Haiti. PLoS Med 2011; 8:e1001095. doi:101371/journalpmed1001095.

24. Human Rights Watch. A testing challenge: the experience of Lesotho's universal HIV counseling and testing campaign. New York, NY: Human Rights Watch, 2008.

25. Tumwesigye E, Wana G, Kasasa S, Muganzi E, Nuwaha F. High uptake of home-based, district-wide, HIV counseling and testing in Uganda. AIDS Patient Care STDS 2010; 24:735-41.

26. Faal M, Naidoo N, Glencross DK, Venter WD, Osih R. Providing immediate CD4 count results at HIV testing improves ART initiation. J Acquir Immune Defic Syndr 2011 [published online ahead of print 18 August 2011].

27. Zachariah R, Reid SD, Chaillet $P$, Massaquoi M, Schouten EJ, Harries AD. Viewpoint: why do we need a point-of-care CD4 test for low-income countries? Trop Med Int Health 2011; 16:37-41.

28. De Cock KM, Mbori-Ngacha D, Marum E. Shadow on the continent: public health and HIV/AIDS in Africa in the 21st century. Lancet 2002; 360:67-72. 